\title{
THE BRITISH MEDICAL ASSOCIATION JUNIOR MEMBERS' FORUM, 1968
}

\author{
Major W. E. I. FORSYTHE-JAUCH, M.A., M.B., B.Chir., R.A.M.C. \\ Medical Officer, The Coldstream Guards
}

Introduction

THE Junior Members' Forum of the British Medical Association was held at Birmingham University on 6 and 7 April 1968. Approximately 80 doctors attended, including an advisory group of senior members of the B.M.A. Almost all the doctors were " Representatives", that is, they represented their B.M.A. Region, the Public Health Services, Medical Teaching, Junior Hospital Staff, and one doctor represented each of the three Services. A few were present who came, not as representatives, but in their own right as junior members of the B.M.A. A junior member was defined as one who was less than forty years of age and who had been registered for less than eleven years. Accommodation was provided in High Hall, one of the residential blocks of the University, and the discussions took place in the conference room on the ground floor. The hospitality given by the Association was admirable, the rooms were the height of comfort, and no one failed to attend the wine-tasting session given by the Hastings Wine Club.

\section{The debates}

As a relative newcomer to medical politics I was very honoured to be invited to attend the Forum as representative of the Royal Army Medical Corps. To me as a newcomer it was astonishing to hear the high standard of the debates and the grasp by the doctors of medical politics. Having been recently co-opted to the Armed Forces Committee of the British Medical Association as a junior non-specialist, I was able to approach the Chairman of that Committee, Major-General J. C. Barnetson, for details of the situation of the Corps in negotiations about medical officers' salaries and career prospects. General Barnetson brought me well up to date on the immense amount of work which has been going on behind the scenes to improve our position. With my knowledge that all that should be done had in fact been initiated, the Forum was asked by me to consider the motion:

"That the British Medical Association be commended for the efforts they have made in attempting to obtain fair payment for doctors in the Armed Forces: That the Council be further exhorted to continue their efforts."

A debate was opened on this motion, and civilian practitioners proposed three amendments. The first was that the words " . . . . also in view of the serious effect this uncertainty has on recruiting" be added. This was approved. The second amendment was that the words " fair payment" should be' substituted by " . . . a adequate career and salary structure ....". This, too, was approved. A third amendment was resisted by me: it was to have added the words "... . for doctors in the Armed Forces, in hospital teaching posts and research posts. ...". I opposed this amendment not because I considered it to be unworthy, but because the Armed Forces are in a special situation. It was emphasised that the uncertainty about the future was having a bad effect on the Armed Forces Medical Services: resignations and retirements well outbalanced recruitment in a proportion of approximately five to one, and this was a state which could not go on for ever. Indeed, it was against the national interest to allow it to do so. It 
was suggested that the amendment be defeated, for it would reduce the strength of the motion, which was not a parochial matter but underlined an aspect of national security. This amendment was defeated. Eventually the motion was approved nem. con.

The debates on a large variety of other subjects of lesser interest to the Corps took place all day on Saturday, 6 April and on the morning of Sunday, 7 April. These have all been reported in the Supplement to the British Medical Journal (1968). Those points of particular interest to the Army were:-

A great deal of interest was shown by the Forum in group practice and ancillary services. By and large, doctors welcomed nurses and other health visitors in their practices; in fact, what they were seeking was the system which we are used to in the Army, the medical centre with its staff of medical assistants, clerk and driver, with special investigation facilities at military hospitals, a readily available ambulance service, and easy access to outpatients and specialists.

Interest was shown in the possibility of organizing hospitals as are military hospitals, with senior consultants as officers in charge of Divisions, and an elected clinical chief equivalent to Officer Commanding the hospital. A motion was carried that hospitals should have junior doctor representation at the highest level. In fact, it is apparent from this debate that many hospitals already have such representation on the governing body.

A long debate was held on how to assess a good standard of medicine in general practice and how to reward it appropriately. The Forum eventually came round to feeling that some form of inspection would be necessary, as is the case apparently in the United States and, of course, in the Forces.

\section{Discussions with civilian practitioners}

Having been out of civilian practice for about ten years, I was struck by the changed attitude of our civilian colleagues. If they considered methods of organisation of medical facilities to be bad they did not hesitate to say so. Many of the doctors had taken positive action in bringing their practices and hospitals up to date, often, one felt, against resistance from senior colleagues. No one appeared to feel any hesitation to challenge established usage which, heretofore, had been carried on for no other reason but its own sake.

It was also noticeable how extremely uninformed were the civilian doctors about medical organisation in the Services. They knew about our pay problems and worries about careers. They were particularly interested to hear of the organisation of my own medical centre, supported as I have indicated above. The fact that Army doctors are sent on paid diploma and refresher courses also elicited envy. The long hours of work, the high expenses, and the difficulties in finding leave reliefs, in all these matters there appeared to be little doubt that in the Services we have considerable advantage over our civilian colleagues.

\section{Conclusion}

My overall impression of the two days' meeting was of the enormous energy and drive of the Junior Members of the B.M.A. They were far from being concerned with recrimination, national malaise, or an attitude of "I'm all right, Jack". One had the feeling of a vigorous iconoclasm, and that they, at any rate, were determined to do all that was possible to improve the life of both patients and doctors. 